\title{
Glypican-I Overexpression in Different Types of Breast Cancers
}

\author{
Fatemah OFO Alshammari ${ }^{1}$ \\ Yousef M Al-Saraireh (1D) ${ }^{2}$ \\ Ahmed MM Youssef $\left(\mathbb{D}^{3}\right.$ \\ Yahya M AL-sarayra ${ }^{4}$ \\ Hamzeh Mohammad \\ Alrawashdeh ${ }^{5}$
}

'Department of Medical Lab technology, Faculty of health sciences, The Public Authority for Applied Education and Training, Kuwait, Kuwait; ${ }^{2}$ Department of Pharmacology, Faculty of Medicine, Mutah University, Al-karak, Jordan;

${ }^{3}$ Department of Pharmacology, Faculty of Pharmacy, Mutah University, Al-karak, Jordan; ${ }^{4} \mathrm{Al}$-karak Governmental hospital, Al-Karak, Jordan; ${ }^{5}$ Department of Ophthalmology, Sharif Eye Centers, Irbid, Jordan
Correspondence: Yousef M Al-Saraireh Department of Pharmacology, Faculty of Medicine, Mutah University, PO. Box: 7, Al-karak, 61710, Jordan

Tel +962799172658

Email Yousef.sar@mutah.edu.jo
Purpose: Treatment of metastatic breast cancer patients is challenging and remains a major underlying cause of female mortality. Understanding molecular alterations in tumor development is critical to identify novel biomarkers and targets for cancer diagnosis and therapy. One of the aberrant cancer expressions gaining recent research interest is glypican-1. Several studies reported strong glypican-1 expression in various types of human cancers. However, none of these investigated glypican-1 expression in a large cohort of breast cancer histopathological subtypes.

Patients and Methods: Immunohistochemistry was used to assess glypican-1 expression in 220 breast cancer patients and its relation to demographic and clinical features, as well as important prognostic immunohistochemical markers for breast cancer.

Results: Intense glypican-1 expression was recognized in all breast cancer histopathological subtypes. Normal, healthy breast tissue displayed a heterogeneous low expression $(20 \%)$. Importantly, a strong differential in glypican-1 expression was determined between normal and malignant breast tissues. Moreover, there was a significantly high rate of glypican-1 expression in advanced grades of breast cancer patients and larger tumor sizes. Unfortunately, the glypican-1 expression demonstrated no obvious relationship with the expression of various biomarkers in breast cancer.

Conclusion: This study may establish glypican-1 as a promising new therapeutic target for the development of therapy in breast cancer.

Keywords: cancer, glypicans, immunohistochemistry, protoglycans, heparan sulfate proteoglycans

\section{Introduction}

Breast cancer is the most prevalent type of cancer among women, making up $11.6 \%$ of the cancer morbidity burden and $6.6 \%$ of the cancer mortality rate worldwide. In 2018, 2 million women (24.2\%) were newly diagnosed with breast cancer and more than 0.6 million $(15.0 \%)$ women died from this cancer worldwide. ${ }^{1}$ Despite the substantial improvement in prognosis of breast cancer patients, approximately onethird of the patients die from metastatic disease, especially in the brain. Even with the recent advances in the treatment of breast cancer, concerns about diagnostic methods and effective treatment options remain unresolved. ${ }^{2,3}$ Therefore, new biomarkers for the detection of early-stage breast cancer and new therapies for better management of metastatic disease are urgently needed.

Glypicans are a family of proteins belonging to heparan sulfate proteoglycans (HSPGs). They are attached to extracellular surfaces via a glycosylphosphatidylinositol anchor. ${ }^{4}$ To date, there are six types comprising this family 
in mammals, recognized as Glypican-1 to Glypican-6. These are predominantly expressed during organ development, particularly in morphogenesis, and their levels change in a stage and tissue-specific manner. ${ }^{5,6}$ Their main function is believed to control cell signalling through cell interactions, Wnt and Sonic hedgehog (Shh) activation, and growth factor binding, such as fibroblast growth factor (FGF), insulin-like growth factor (IGF), and vascular endothelial growth factor (VEGF). These signalling pathways participate in the regulation of cell proliferation, motility, differentiation, organ development and metabolism. $^{7}$

Several studies demonstrated the role of glypicans in regulating the cell growth and tumorigenesis in many cancers. $^{8}$ Of recent importance is the aberrant expression of glypican-1 in several types of cancers and its association with cancer development. Glypican-1 expression was found to be higher in patients with pancreatic cancer than in chronic pancreatitis patients and healthy controls. ${ }^{9}$ This expression was significantly associated with clinical stages, and implicated poor prognosis. ${ }^{10,11}$ Moreover, glypican-1 was mainly localized to pancreatic cancer cells in comparison to normal cells. When glypican-1 was knocked down, tumor growth and mitotic response to fibroblast growth factor-2 decreased. ${ }^{12}$ Apart from pancreatic cancer, glypican-1 was overexpressed in breast cancer tissues, ${ }^{12}$ ovarian malignant tumors ${ }^{13}$ gliomas, ${ }^{14}$ glioblastoma, ${ }^{15}$ uterine cervical cancer, ${ }^{16}$ prostate cancerous epithelial cells and esophageal cancer. ${ }^{11,17}$ Importantly, glypican-1 levels were elevated in the patient's peripheral blood and suggesting they could be a promising biomarker for the detection of glypican-1 expressing cancers. ${ }^{18,19}$

Whilst there have been some studies looking for glypican-1 role in tumors, only one study attempted to explore glypican-1 expression in a small panel of breast cancers. $^{12}$ Therefore, this study aims to examine glypican1 expression over a large scale of breast cancer clinical samples and its relation to histopathological features, as well as important prognostic immunohistochemical markers for breast cancer.

\section{Materials and Methods}

\section{Tissue Specimens}

Prior to the start of study, an exemption of written informed consent for the use of breast tissue samples was obtained from the Institutional Review and Ethics
Committee, Faculty of Medicine, University of Mutah. The study complies with regulations set by Declaration of Helsinki (2013). Surgically resected tissue specimens from breast cancer patients were processed to create paraffin-embedded tissue blocks. These resected tissue specimens were obtained after surgical operations at King Abdullah University Hospital, Irbid and King Hussein Medical Hospital, Royal Medical Services, in Amman, Jordan during the five-year period (2015-2020). The panel of tissues consists of five normal breast tissues, three benign breast cancers and two hundred and twenty malignant types of breast cancers. Patients who underwent preoperative chemotherapy or radiotherapy were excluded from the study. From patients' file, data about the biomarker expression androgen receptor (AR), epidermal growth factor receptor (EGFR), estrogen receptor (ER), progesterone receptor $(\mathrm{PR})$, epidermal growth factor receptor 2 (HER-2), P53 and Ki67 and demographic and clinicopathologic characteristics, including the age of patients, tumor pathological subtypes, histological stages, tumor sizes, histological grades and status of lymph node metastasis were collected. All the patients' personal and clinical data were confidential and kept anonymous.

\section{Immunohistochemistry}

Immunohistochemical detection of glypican-1 was carried out using a peroxidase polymer-based detection system. Archived paraffin-embedded (FFPE) tissue sections (5 $\mu \mathrm{m})$ were de-waxed in xylene and progressively rehydrated in decreasing dilutions of ethanol. Sections were then immersed in 3\% hydrogen peroxide solution for 5 minutes at room temperature, followed by a washing in phosphate buffered saline (PBS). Heat-induced antigen retrieval was performed by microwaving at $650 \mathrm{~W}$ in 10 $\mathrm{mM}$ citrate buffer, $\mathrm{pH}$ 6.0, for 20 minutes. Following a wash in PBS, sections were first incubated with $2.5 \%$ normal goat serum to block non-specific binding sites for antibodies at room temperature for 20 minutes. Thereafter, sections were covered with rabbit polyclonal antibody specific for glypican-1 (ab217339) (Abcam, UK) at a concentration of $5 \mu \mathrm{g} / \mathrm{mL}$ for overnight at $4^{\circ} \mathrm{C}$. Following a wash in PBS, sections were covered with goat anti-rabbit peroxidase polymer at room temperature for 30 minutes (MP-7451, Vector Laboratories, Burlingame, USA). Following a wash in PBS immunoreactivity was visualized by incubating sections with diaminobenzidine chromogen solution as a substrate (Vector Laboratories Ltd, Peterborough, UK) for 3-5 minutes at 
room temperature. After that, tissue sections were counterstained with Harris's haematoxylin solution to establish the presence and absence of glypican-1 immunoreactivity and its cellular localization. Tissue sections were dehydrated and finally mounted with glass coverslips. The resulting slides were assessed using a Leica DMRB microscope (Leica DMRB, Wetzlar, Germany) and images were digitally captured and processed using AcQuis Biosystem (Synoptics, Cambridge, UK).

\section{Scoring}

Glypican-1 expression was manually and semiquantitatively evaluated by three pathologists. The criteria for glypican-1 positivity was based on the intensity and percentage of tumor cells showing expression. Cells displaying membranous or cytoplasmic immunostaining were deemed positive for glypican-1 expression. The scores were presented in the following order: negative (0), low (1), moderate (2), and strong (3). The score "negative" was allocated to tissues showing no expression at all. Tissues showing expression less than 33\% were assigned a score of "low". A score of "moderate" was applied to tissues showing an expression of $34-66 \%$ of the cells. Tissues displaying an expression in more than $67 \%$ of the cells were allocated a score of "strong".

\section{Statistical Analysis}

The statistical data analysis was performed using the available SPSS-25 statistical package (Statistical Packages for Social Sciences, version 25). Simple frequency and percentage measures were used to present the data. Whenever applicable, Pearson's chi-square test with the application of ANOVA test was used to assess the discrepancies between the continuous variables. A P $<0.05$ was deemed statistically significant for the results.

\section{Results}

\section{Baseline Demographic and Clinicopathologic Features of Breast Cancer Patients}

This study included 220 females with breast cancer, three benign breast fibroadenomas and a control group of five females with normal breast pathology (Table 1). The average age of the participants was $49.7 \pm 12.4$ years. Of the patients, $59.2 \%$ (135 cases) were under 50 years of age, whereas $40.8 \%$ (93 cases) were over 50 years of age. In this study, invasive ductal carcinoma (179 cases, 78.5\%) was the most prevalent pathological subtype of breast cancer patients. Other breast cancer pathological subtypes included 14 Intra-ductal carcinomas (6.1\%), 12 Invasive Lobular carcinomas (5.3\%), six Mucinous Adenocarcinomas (2.6\%), two Invasive Papillary carcinomas $(0.9 \%)$, two Lobular carcinoma in situ $(0.9 \%)$, and the remaining five cases $(2 \%)$ were invasive apocrine carcinoma, Paget's disease, lipid-rich carcinoma, adenoid cystic carcinoma and undifferentiated carcinoma. Just over half of the breast cancer patients were at tumor grade III (51.8\%, 114 cases), while 39.5\% (87 cases) and 8.6\% (19 cases) of patients were at grade II and grade I, respectively. Moreover, more than half of the patients $(61.4 \%$, 135 cases) had cancers with tumor size T2. Other patients were distributed as follows: T1 (10\%, 22 cases), T3 (13.6\%, 30 cases), T4 (7.3\%, 16 cases) and Tis $(7.7 \%$, 17 cases). There were $27.7 \%$ (87 cases) patients with lymph node metastasis, while other patients $(72.3 \%, 159$ cases) were free from lymph node metastasis. Data on immunohistochemical biomarker expression status are summarized in Table 2.

\section{Prevalence of Glypican-I expression}

Glypican-1 immunoreactivity was observed in one normal sample (out of five normal samples) (20\%). This was mainly localized to the cell membrane or cytoplasm, with no substantial staining in the nuclei. However, the immunoreactivity was characterized as low, less intense and heterogeneous from one area to another within the same section. Figure 1 shows the scoring criteria for glypican-1 expression. All the benign breast tumors showed glypican1 immunoreactivity. The immunostaining was more intense than in normal cases, but scored a low expression (Figure 2) (Table 1). The comparison between glypican-1 expression in breast tissues of benign tumor and normal showed no association ( $\mathrm{P}=0.175)$.

Glypican-1 immunoreactivity was identified in all the patient cases of primary breast tumors (100\%) (Figure 2) (Table 1). The immunoreactivity was intense and no evidence of intratumor heterogeneity was seen along all sections examined. In a high number of breast tumors, glypican-1 expression was found strongly in 68.6\% (151 cases) of patient cases, while the expression in the remaining patient cases was found as low $(11.4 \%, 25$ cases) and moderate $(20 \%, 44$ cases). Importantly, there was a significant difference in glypican-1 expression between normal samples and primary breast cancer samples $(\mathrm{P}=$ 0.033). However, no statistical difference in glypican-1 
Table I Relationship Between Glypican-I expression and Demographic and Clinicopathological Features

\begin{tabular}{|c|c|c|c|c|c|}
\hline Characteristic & Negative & Low & Moderate & Strong & $P$ value \\
\hline \multicolumn{6}{|l|}{ Age (years) } \\
\hline$\leq 50(n=135,59.3 \%)$ & $4(3 \%)$ & 19 (14.1\%) & $28(20.7 \%)$ & $84(62.2 \%)$ & 0.178 \\
\hline$>50(n=93,40.7 \%)$ & $0(0 \%)$ & $10(10.8 \%)$ & $16(17.2 \%)$ & 67 (72\%) & \\
\hline \multicolumn{6}{|l|}{ Histological type } \\
\hline Normal $(n=5,2.2 \%)$ & $4(80 \%)$ & I (20\%) & $0(0 \%)$ & $0(0 \%)$ & \\
\hline Benign $(n=3,1.3 \%)$ & $0(0 \%)$ & $3(100 \%)$ & $0(0 \%)$ & $0(0 \%)$ & \\
\hline Invasive ductal carcinoma $(n=\mid 79,78.5 \%)$ & $0(0 \%)$ & $19(10.6 \%)$ & $36(20.1 \%)$ & $124(69.3 \%)$ & \\
\hline Invasive lobular carcinoma $(n=12,5.3 \%)$ & $0(0 \%)$ & $2(16.7 \%)$ & I (8.3\%) & $9(75 \%)$ & \\
\hline Intra-ductal carcinoma $(n=\mid 4,6.1 \%)$ & $0(0 \%)$ & $3(21.4 \%)$ & $3(14.3 \%)$ & $9(64.3 \%)$ & \\
\hline Mucinous adenocarcinoma $(n=6,2.6 \%)$ & $0(0 \%)$ & $0(0 \%)$ & $2(33.3 \%)$ & $4(66.7 \%)$ & \\
\hline Invasive papillary carcinoma $(n=2,0.9 \%)$ & $0(0 \%)$ & $0(0 \%)$ & $0(0 \%)$ & $2(100 \%)$ & 0.011 \\
\hline Lobular carcinoma in situ $(n=2,0.9 \%)$ & $0(0 \%)$ & $0(0 \%)$ & $2(100 \%)$ & $0(0 \%)$ & \\
\hline Invasive apocrine carcinoma $(n=I, 0.4 \%)$ & $0(0 \%)$ & I (I00\%) & $0(0 \%)$ & $0(0 \%)$ & \\
\hline Paget's disease $(n=I, 0.4 \%)$ & $0(0 \%)$ & $0(0 \%)$ & $\mathrm{I}(100 \%)$ & $0(0 \%)$ & \\
\hline Lipid-rich carcinoma $(n=I, 0.4 \%)$ & $0(0 \%)$ & $0(0 \%)$ & $0(0 \%)$ & I (I00\%) & \\
\hline Adenoid cystic carcinoma $(n=1,0.4 \%)$ & $0(0 \%)$ & $0(0 \%)$ & $0(0 \%)$ & I (I00\%) & \\
\hline Undifferentiated carcinoma $(n=I, 0.4 \%)$ & $0(0 \%)$ & $0(0 \%)$ & $0(0 \%)$ & I (100\%) & \\
\hline \multicolumn{6}{|l|}{ Histological grade } \\
\hline$I(n=19,8.6 \%)$ & $0(0 \%)$ & $4(16 \%)$ & $5(11.4 \%)$ & $10(6.6 \%)$ & 0.037 \\
\hline II $(n=87,39.5 \%)$ & $0(0 \%)$ & $9(36 \%)$ & $12(27.3 \%)$ & $66(43.7 \%)$ & \\
\hline III $(n=|| 4,5 \mid .8 \%)$ & $0(0 \%)$ & $12(48 \%)$ & 27 (6I.4\%) & 75 (49.7\%) & \\
\hline \multicolumn{6}{|l|}{ Lymph node metastasis } \\
\hline Yes $(n=6 I, 27.7 \%)$ & $0(0 \%)$ & $3(4.9 \%)$ & $13(2 \mid .3 \%)$ & $45(73.8 \%)$ & 0.169 \\
\hline No $(n=159,72.3 \%)$ & $0(0 \%)$ & $22(13.8 \%)$ & 31 (19.5\%) & $106(66.7 \%)$ & \\
\hline \multicolumn{6}{|l|}{ Tumour size } \\
\hline Tis $(n=17,7.7 \%)$ & $0(0 \%)$ & 5 (29.4\%) & $4(23.5 \%)$ & $8(47.1 \%)$ & \\
\hline TI (n=22, 10\%) & $0(0 \%)$ & $3(13.6 \%)$ & 8 (36.4\%) & II (50\%) & \\
\hline T2 $(n=\mid 35,61.4 \%)$ & $0(0 \%)$ & $17(12.6 \%)$ & $22(16.3 \%)$ & $96(71.1 \%)$ & 0.003 \\
\hline T3 $(n=30,13.6 \%)$ & $0(0 \%)$ & $0(0 \%)$ & $5(16.7 \%)$ & $25(83.3 \%)$ & \\
\hline T4 $(n=16,7.3 \%)$ & $0(0 \%)$ & $0(0 \%)$ & 5 (3I.3\%) & II (68.8\%) & \\
\hline
\end{tabular}

expression between benign breast samples and primary breast cancer samples could be determined.

Several significant associations were elaborated between glypican-1 expression and various clinicopathologic features, including tumor grade and tumor size $(\mathrm{P}<$ 0.05 ) (Table 1). There was a higher frequency of glypican1 expression in tumor grade III $(51.8 \%, 114$ cases $)$ than grade II (39.5\%,87 cases) and grade I (8.6\%,19 cases). Moreover, high glypican-1 expression was more frequently found in larger tumour sizes as follows: T4 (68.8\%, 11 cases), T3 (83.3\%, 25 cases), T2 (71.1\%, 96 cases), T1 (50\%, 11 cases) and Tis (47.1\%, 8cases). In contrast, no apparent relationship was determined between glypican-1 expression and age of patients, lymph node status, and various biomarker expressions (Table 2).
As the invasive ductal carcinoma is the major breast cancer type in this study (179 cases), the relationships between glypican-1 expression and various clinicopathologic features of invasive ductal carcinoma patients were further analyzed. There were significant associations with tumor grade and tumor size $(\mathrm{P}<0.05)$. Higher frequency of glypican-1 expression was found in advanced grades of disease and large tumor sizes compared with early grades of disease and small tumor sizes. No significant relationship was determined between glypican-1 expression and other clinicopathologic features including age of patients and lymph node status. Additionally, further analysis of the relationships between glypican-1 expression and biomarkers expressions particularly HER-2, ER and PR was performed. Here, a model of eight possible different 
Table 2 Relationship Between Glypican-I expression and Immunohistochemical Markers

\begin{tabular}{|c|c|c|c|c|}
\hline Immunohistochemical Marker & Low & Moderate & Strong & $P$ value \\
\hline \multicolumn{5}{|l|}{ AR } \\
\hline Positive $(n=|2|, 55 \%)$ & $15(12.4 \%)$ & $28(23.1 \%)$ & $78(64.5 \%)$ & 0.323 \\
\hline Negative $(n=99,45 \%)$ & $10(10.1 \%)$ & $16(16.2 \%)$ & $73(73.7 \%)$ & \\
\hline \multicolumn{5}{|l|}{ ER } \\
\hline Positive $(n=125,56.8 \%)$ & 14 (1I.2\%) & $29(23.2 \%)$ & $82(65.6 \%)$ & 0.391 \\
\hline Negative $(n=95,43.2 \%)$ & $11(11.6 \%)$ & $15(15.8 \%)$ & $69(72.6 \%)$ & \\
\hline \multicolumn{5}{|l|}{ PR } \\
\hline Positive $(n=100,45.5 \%)$ & II (II\%) & $23(23 \%)$ & $66(66 \%)$ & 0.597 \\
\hline Negative $(n=120,54.5 \%)$ & 14 (11.7\%) & $21(17.5 \%)$ & $85(70.8 \%)$ & \\
\hline \multicolumn{5}{|l|}{ EGFR } \\
\hline Positive $(n=4 I, 18.6 \%)$ & $6(14.6 \%)$ & 7 (I7.l\%) & $28(68.3 \%)$ & 0.708 \\
\hline Negative $(n=179,81.4 \%)$ & $19(10.6 \%)$ & $37(20.7 \%)$ & $123(68.7 \%)$ & \\
\hline \multicolumn{5}{|l|}{ HER2 } \\
\hline Positive $(n=157,71.4 \%)$ & $18(11.5 \%)$ & $34(21.7 \%)$ & 105 (66.9\%) & 0.605 \\
\hline Negative $(n=63,28.6 \%)$ & 7 (11.1\%) & $10(15.9 \%)$ & $64(73 \%)$ & \\
\hline \multicolumn{5}{|l|}{ P53 } \\
\hline Positive $(n=156,70.9 \%)$ & $20(12.8 \%)$ & $28(17.9 \%)$ & $108(69.2 \%)$ & 0.340 \\
\hline Negative $(n=64,29.1 \%)$ & $5(7.8 \%)$ & $16(25 \%)$ & $43(67.2 \%)$ & \\
\hline \multicolumn{5}{|l|}{ Ki-67 } \\
\hline$<14 \%(n=111,50.5 \%)$ & $31(11.9 \%)$ & $21(19.3 \%)$ & 75 (68.8\%) & 0.942 \\
\hline$>14 \%(n=109,49.5 \%)$ & $12(10.8 \%)$ & $23(20.7 \%)$ & $76(68.5 \%)$ & \\
\hline
\end{tabular}

categorical combinations was generated based on expression status (positive $(+)$ and/or negative $(-)$ ) of HER-2, ER and PR, as shown in Table 3. Results showed that there was no significant association between glypican-1 expression and different categorical combinations of biomarker expressions $(\mathrm{P}=0.12)$.

\section{Discussion}

Breast cancer remains a major global burden and challenging obstacle for health care systems. ${ }^{1}$ Most patients have metastatic breast cancer at the first diagnosis. Conventional treatments for metastatic breast cancer patients are quite a lot less effective and cause serious toxicities. ${ }^{3}$ As a result, new therapies and diagnostic biomarkers are urgently needed to address this problem. In this regard, modern rational strategies in the development of new drugs are focused on changes in cancer cells' molecular biology. ${ }^{20}$ One of the emerging molecules in cancer development and progression that gained recent interest is glypican-1. Compared to other types of cancers, only one study has investigated the expression of glypican1 in a small set of breast cancers. ${ }^{12}$ Therefore, this study aimed to investigate glypican-1 expression in a large cohort of different types of breast cancers.

Several studies demonstrated that aberrant expression of individual forms of glypicans influences the development of many cancers including breast cancer. Glypican-1 expression was found to enhance the mitogenic response of breast cancer cell lines to different heparin-binding growth factors, suggesting that up-regulation of glypican1 could play a role in breast cancer progression. ${ }^{12}$ Moreover, the glypican-1 gene's expression in MDA-MB -231 breast cancer cell line may indicate its greater metastatic potential. ${ }^{21}$ Many studies implicating glypican-3 in breast cancer development showed that glypican-3 expression was down-regulated in breast cancer partly by means of hypermethylation of the glypican-3-promoter. ${ }^{22,23}$ Furthermore, ectopic glypican-3 expression led to reduction in the motility and growth of breast cancer cells by inhibiting IGF and Wnt signalling. ${ }^{23,24}$ A lesser studied member of glypican family is glypican-4. Knockdown of glypican-4 was found to enhance cell motility, invasion, and growth of breast cancer cells. ${ }^{25}$ Another glypican family member, glypican-6, appeared to play a critical 

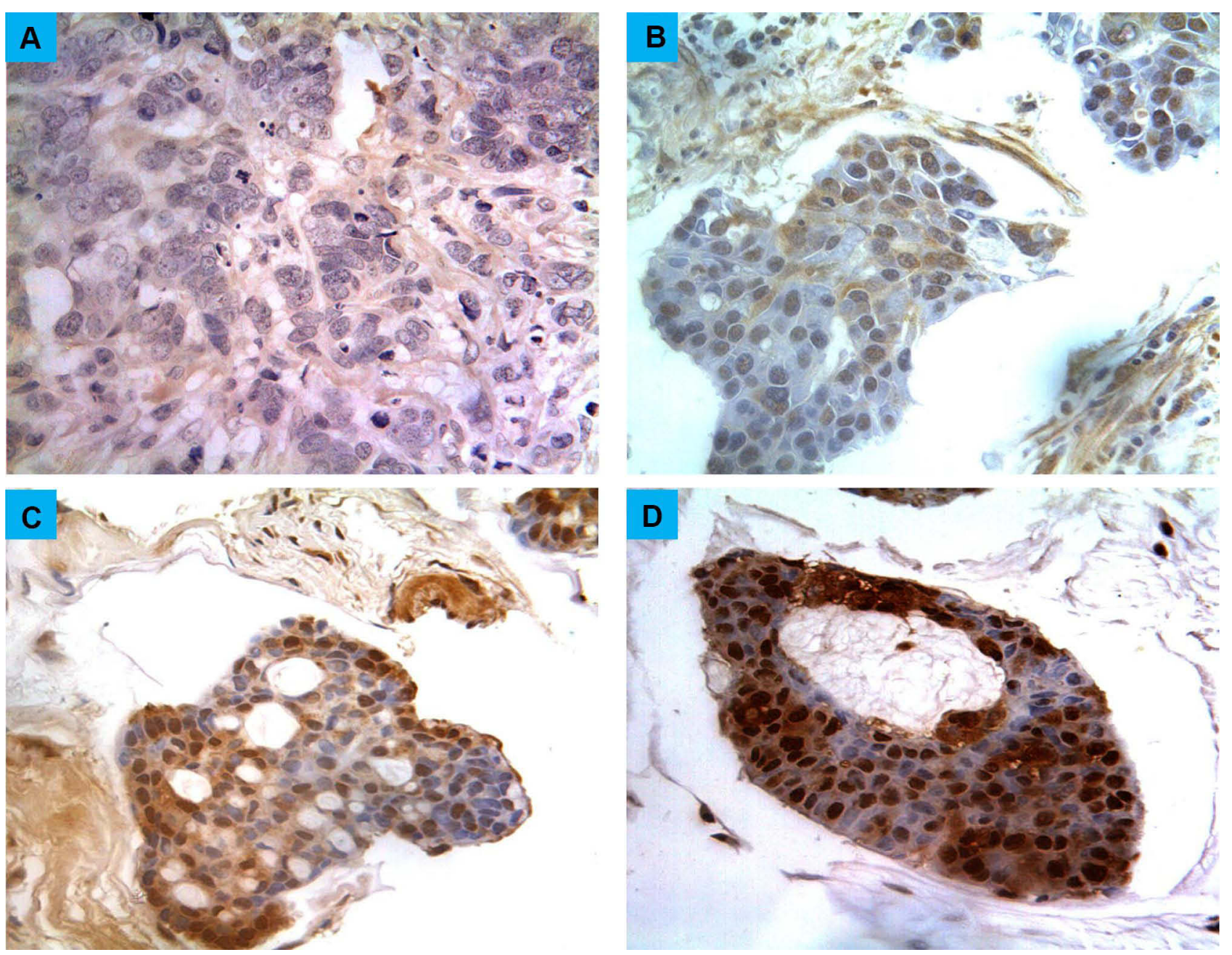

Figure I Different scores of glypican-I expression in breast cancers. (A) Score "negative" showing no expression in the tissue at all. (B) Score "low" showing expression less than $33 \%$ of cells, (C) score "moderate" showing expression in $34-66 \%$ of the cells, (D) score "strong" showing expression in more than $67 \%$ of the cells. Magnification (X400).

role in enhancing invasive migratory potential of breast cancer cells. This was indirectly promoted by stimulation of Wnt5a expression, which in turn led to activation of $\mathrm{p} 38$ mitogen-activated protein kinase (MAPK) and Jun $\mathrm{N}$-terminal kinase (JNK). ${ }^{26}$ A quest for additional research about mechanistic role of glypicans particularly glypican-1 in breast cancer progression remains elusive.

The importance and expression of glypican-1 in several cancers have been demonstrated by several studies. ${ }^{9,10,12,14,15,27}$ Since the only study of glypican-1 expression in breast cancer was done on a small number of intra-ductal and lobular carcinomas, ${ }^{12}$ this study is pioneering in including large, diverse and common subtypes of breast cancer. Here, we report glypican-1 overexpression in all subtypes of breast cancer, particularly invasive ductal carcinoma, which is a new finding. This type of cancer was the major breast cancer subtype in our cohort because it accounts for $70-80 \%$ of breast cancer cases. ${ }^{1}$ As well as this, intra-ductal and lobular carcinomas also showed a similar means of expression. Moreover, normal breast tissues showed a faint low glypican-1 expression. This is consistent with the earlier breast cancer study, demonstrating glypican-1 overexpression in such breast cancer subtypes compared to weak expression in corresponding to normal tissues. ${ }^{12}$ Furthermore, these findings are also consistent with previous studies demonstrating high glypican-1 expression in pancreatic cancer, ${ }^{9}$ ovarian malignant tumor ${ }^{13}$ gliomas, ${ }^{14}$ uterine cervical cancer, ${ }^{16}$ prostate cancerous epithelial cells and esophageal cancer, ${ }^{11,17}$ compared to normal tissues. Importantly, there was a significantly higher frequency of glypican-1 expression in advanced grades of disease than early grades of disease, and a significantly high glypican-1 expression was found in large diameter tumors than in small diameter 

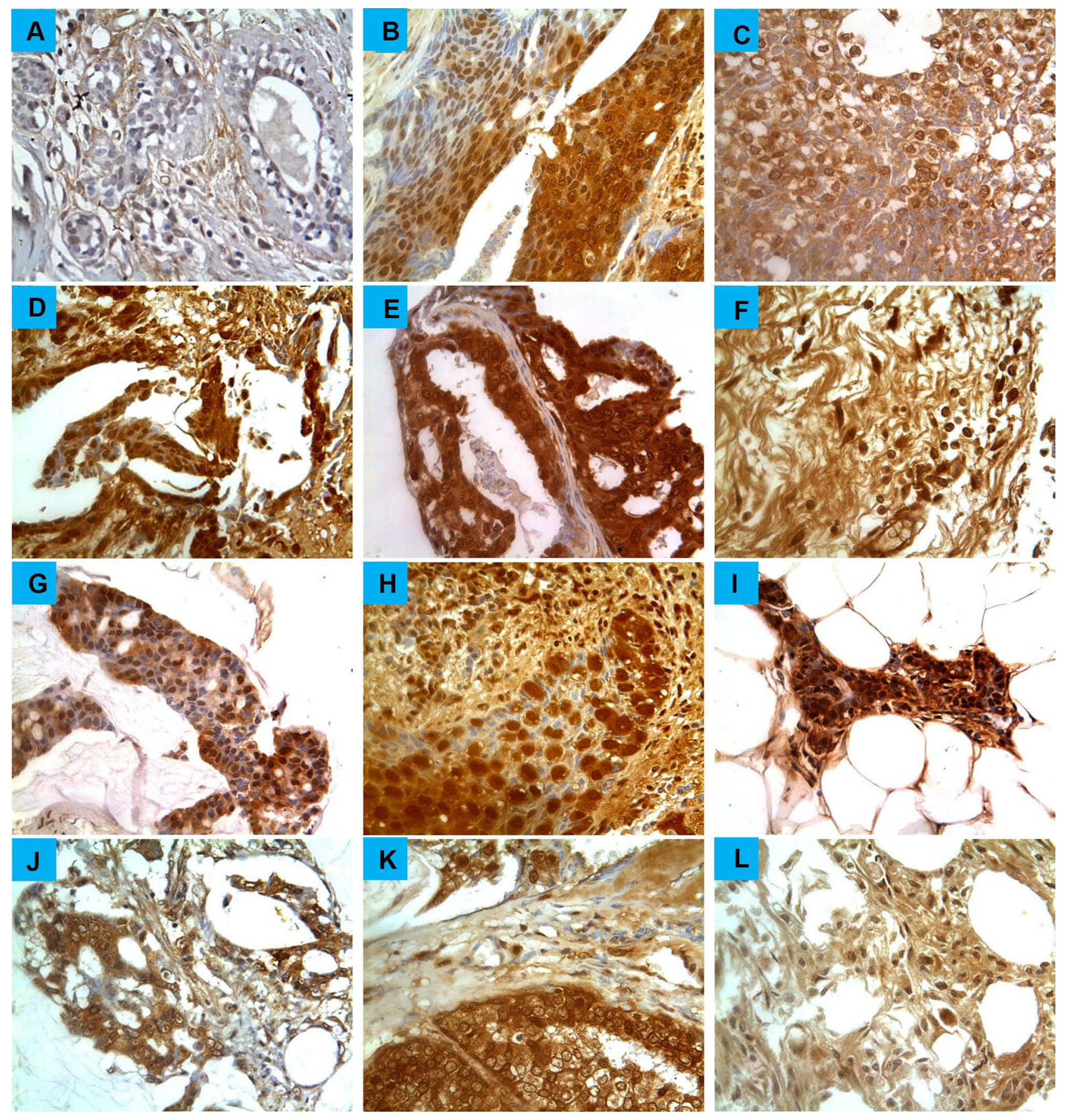

Figure 2 Glypican-I expression in breast cancers. Tumors were classified on the basis of histological type. (A) Normal breast tissue (B) invasive ductal carcinoma, (C) invasive lobular carcinoma, (D) invasive papillary carcinoma, (E) intra-ductal carcinoma, (F) invasive apocrine carcinoma, (G) Mucinous carcinoma, (H) Paget's disease and (I) lobular carcinoma in situ (J) Lipid-rich carcinoma (K) Adenoid cystic carcinoma (L) and Undifferentiated carcinoma. Magnification (X400).

tumors. These observations are in agreement with a previous study demonstrating high levels of glypican-1 found in late grade and larger tumors of pancreatic ductal adenocarcinoma. $^{28}$

The principle of designing selective therapies relies on a molecular entity that is uniquely and differentially expressed between normal and tumorous tissues. Here, there was a strong differential in glypican-1 expression between breast normal and tumorous tissues. Several earlier studies have shown that glypican-1 expression can differentiate between normal tissues and multiple tumor entities. $^{9,29-33}$ For instance, glypican-1 was able to discriminate human pancreatic cancer from chronic pancreatitis and normal pancreas tissues. ${ }^{9}$ Furthermore, glypican-1 
Table 3 Relationship Between Glypican-I expression and Clinicopathological Features and Categorical Combinations of HER-2, ER and PR in invasive ductal carcinomas.

\begin{tabular}{|c|c|c|c|c|c|}
\hline Characteristic & Negative & Low & Moderate & Strong & $P$ value \\
\hline \multicolumn{6}{|l|}{ Age (years) } \\
\hline$\leq 50(n=104,58.1 \%)$ & $0(0 \%)$ & $8(7.7 \%)$ & $23(22.1 \%)$ & $73(70.2 \%)$ & 0.378 \\
\hline$>50(n=75,41.9 \%)$ & $0(0 \%)$ & $8(10.7 \%)$ & $13(17.3 \%)$ & 54 (72\%) & \\
\hline \multicolumn{6}{|l|}{ Histological grade } \\
\hline I $(n=3,1.7 \%)$ & $0(0 \%)$ & $0(0 \%)$ & I (33.3\%) & $2(66.7 \%)$ & 0.042 \\
\hline II (n=75, 4I.9\%) & $0(0 \%)$ & $6(8 \%)$ & II (I4.7\%) & $58(77.3 \%)$ & \\
\hline III (n=I0I, 56.4\%) & $0(0 \%)$ & $10(9.9 \%)$ & $24(23.8 \%)$ & $67(66.3 \%)$ & \\
\hline \multicolumn{6}{|l|}{ Lymph node metastasis } \\
\hline Yes $(n=54,30.2 \%)$ & $0(0 \%)$ & $2(3.7 \%)$ & $13(24.1 \%)$ & 39 (72.2\%) & 0.232 \\
\hline No $(n=125,69.8 \%)$ & $0(0 \%)$ & 14 (11.2\%) & $23(18.4 \%)$ & 88 (70.4\%) & \\
\hline \multicolumn{6}{|l|}{ Tumour size } \\
\hline Tis $(n=I, 0.6 \%)$ & $0(0 \%)$ & $0(0 \%)$ & $0(0 \%)$ & I (I00\%) & \\
\hline $\operatorname{TI}(n=17,9.5 \%)$ & $0(0 \%)$ & $2(11.8 \%)$ & 7 (4I.2\%) & 8 (47.I\%) & \\
\hline $\mathrm{T} 2(\mathrm{n}=119,66.5 \%)$ & $0(0 \%)$ & $14(11.8 \%)$ & $20(16.8 \%)$ & 85 (71.4\%) & 0.042 \\
\hline T3 $(n=26,14.5 \%)$ & $0(0 \%)$ & $0(0 \%)$ & $5(19.2 \%)$ & $21(80.8 \%)$ & \\
\hline $\mathrm{T} 4(\mathrm{n}=16,8.9 \%)$ & $0(0 \%)$ & $0(0 \%)$ & $4(25 \%)$ & 12 (75\%) & \\
\hline \multicolumn{6}{|l|}{ Categorical combinations } \\
\hline Her2(+),Pr(-),ER(-) $(n=48,26.8 \%)$ & $0(0 \%)$ & $3(6.3 \%)$ & 7 (14.6\%) & $38(79.2 \%)$ & \\
\hline Her2(+),Pr(+),ER(-) (n=7, 3.9\%) & $0(0 \%)$ & I (14.3\%) & $2(28.6 \%)$ & $4(57.1 \%)$ & \\
\hline Her2(+),Pr(+),ER(+) ( $(=47,26.3 \%)$ & $0(0 \%)$ & $2(4.3 \%)$ & $10(21.3 \%)$ & 35 (74.5\%) & \\
\hline Her2(-),Pr(+),ER(+) $(n=18,10.1 \%)$ & $0(0 \%)$ & $0(0 \%)$ & $4(22.2 \%)$ & 14 (77.8\%) & \\
\hline Her2(+),Pr(-),ER (+) $(n=24,13.4 \%)$ & $0(0 \%)$ & $5(20.8 \%)$ & 7 (29.2\%) & $12(50 \%)$ & 0.12 \\
\hline Her2(-),Pr(-), ER(-) $(n=23,12.8 \%)$ & $0(0 \%)$ & $4(17.4 \%)$ & $4(17.4 \%)$ & $15(65.2 \%)$ & \\
\hline Her2(-),Pr(-), ER(+) (n=8, 4.5\%) & $0(0 \%)$ & I (I2.5\%) & $\mathrm{I}(\mathrm{I} 2.5 \%)$ & $6(75 \%)$ & \\
\hline Her2(-), $\operatorname{Pr}(+), \operatorname{ER}(-)(n=4,2.2 \%)$ & $0(0 \%)$ & $0(0 \%)$ & I (25\%) & $3(75 \%)$ & \\
\hline
\end{tabular}

levels distinguished patients with early and advanced-stage pancreatic cancer from patients with benign pancreatic disease and healthy subjects. ${ }^{29,32,33}$ Additionally, patients with prostate cancer were differentiated from patients with benign prostatic hyperplasia by the detection of glypican-1 levels. $^{30,31}$ Taken together, the expression differential in different cancers and its ability to discriminate between normal and tumor entities, reinforces and supports glypican-1 for future therapeutic exploitation.

The cancer-specific expression of glypican-1 makes it a promising therapeutic target because off-target implications can be avoided. Several studies have developed antibody-based therapeutics, targeting glypican-1 for the treatment of solid tumors. ${ }^{16,34-36}$ The first antibody directed against human and mouse glypican-1 has showed a $70 \%$ inhibition in tumor growth in esophageal squamous cell carcinoma xenograft models. ${ }^{34}$ Additionally, monomethyl auristatin $\mathrm{F}$ conjugated antibody directed towards glypican-1 demonstrated potent inhibition in tumor growth in pancreatic cancer and uterine cervical cancer xenograft models. ${ }^{16,35}$ Surprisingly, chimeric antigen receptor T cells targeting glypican-1 showed strong anticancer activity against solid tumors in xenogeneic and syngeneic marine models without demonstrating any apparent adverse effects. ${ }^{36}$ Overall, these studies show the glypican-1 potential as a therapeutic target for development of novel therapies in breast cancer.

\section{Conclusion}

As there is only one study examining the glypican-1 expression in small and limited subtypes of breast cancer, this is the first study demonstrating strong glypican-1 expression in a diverse and large cohort of breast cancer subtypes. Normal breast tissues demonstrated a less intense heterogeneous low expression of glypican-1. Interestingly, high glypican-1 expression was more 
frequently found in an advanced grade of breast cancer patients and larger tumor size. Importantly, there was a significant differential in glypican-1 expression between normal and tumorous breast tissues. This expression differential makes glypican-1 a novel target for future therapeutic exploitation in breast cancer.

\section{Abbreviations}

$\mathrm{AR}$, androgen receptor; EGFR, epidermal growth factor receptor; ER, estrogen receptor; PR, progesterone receptor; HER-2, epidermal growth factor receptor 2; MAPK, mitogen-activated protein kinase; JNK, Jun N-terminal kinase.

\section{Acknowledgments}

The authors are very thankful to all the associated personnel in any reference who contributed towards the purpose of this research. Moreover, a special thanks to the Deanship of Scientific Research at Mut'ah University. Our sincere thanks are due to Dr. Ahmed Al-abadleh for his kind support and work.

\section{Disclosure}

The authors report no conflicts of interest in this work.

\section{References}

1. Bray F, Ferlay J, Soerjomataram I, Siegel RL, Torre LA, Jemal A. Global cancer statistics 2018: globocan estimates of incidence and mortality worldwide for 36 cancers in 185 countries. CA Cancer J Clin. 2018;68(6):394-424. doi:10.3322/caac.21492

2. Meng Y, Sun J, Wang X, et al. Exosomes: a promising avenue for the diagnosis of breast cancer. Technol Cancer Res Treat. 2019;18:1533033818821421. doi:10.1177/1533033818821421

3. Giordano C, La Camera G, Gelsomino L, et al. The biology of exosomes in breast cancer progression: dissemination, immune evasion and metastatic colonization. Cancers. 2020;12(8):2179. doi:10.3390/cancers 12082179

4. Fico A, Maina F, Dono R. Fine-tuning of cell signaling by glypicans. Cell Mol Life Sci. 2011;68(6):923-929. doi:10.1007/s00018-0077471-6

5. Filmus J, Selleck SB. Glypicans: proteoglycans with a surprise. J Clin Invest. 2001;108(4):497-501. doi:10.1172/JCI13712

6. De Cat B, David G. Developmental roles of the glypicans. Semin Cell Dev Biol. 2001;12(2):117-125. doi:10.1006/scdb.2000.0240

7. Filmus J, Capurro M, Rast J. Glypicans. Genome Biol. 2008;9 (5):224. doi:10.1186/gb-2008-9-5-224

8. Blackhall FH, Merry CL, Davies EJ, Jayson GC. Heparan sulfate proteoglycans and cancer. Br J Cancer. 2001;85(8):1094-1098. doi:10.1054/bjoc.2001.2054

9. Kleeff J, Ishiwata T, Kumbasar A, et al. The cell-surface heparan sulfate proteoglycan glypican-1 regulates growth factor action in pancreatic carcinoma cells and is overexpressed in human pancreatic cancer. J Clin Invest. 1998;102(9):1662-1673. doi:10.1172/JCI4105

10. Duan L, Hu X-Q, Feng D-Y, Lei S-Y, Hu G-H. Gpc-1 may serve as a predictor of perineural invasion and a prognosticator of survival in pancreatic cancer. Asian J Surg. 2013;36(1):7-12. doi:10.1016/j. asjsur.2012.08.001
11. Hara H, Takahashi T, Serada S, et al. Overexpression of glypican-1 implicates poor prognosis and their chemoresistance in oesophageal squamous cell carcinoma. Br J Cancer. 2016;115(1):66-75. doi:10. 1038/bjc.2016.183

12. Matsuda K, Maruyama H, Guo F, et al. Glypican-1 is overexpressed in human breast cancer and modulates the mitogenic effects of multiple heparin-binding growth factors in breast cancer cells. Cancer Res. 2001;61(14):5562-5569.

13. Davies EJ, Blackhall FH, Shanks JH, et al. Distribution and clinical significance of heparan sulfate proteoglycans in ovarian cancer. Clin Cancer Res. 2004;10(15):5178-5186. doi:10.1158/1078-0432.CCR03-0103

14. Su G, Meyer K, Nandini CD, Qiao D, Salamat S, Friedl A. Glypican1 is frequently overexpressed in human gliomas and enhances fgf-2 signaling in glioma cells. Am J Pathol. 2006;168(6):2014-2026. doi:10.2353/ajpath.2006.050800

15. Saito T, Sugiyama K, Hama S, et al. High expression of glypican-1 predicts dissemination and poor prognosis in glioblastomas. World Neurosurg. 2017;105:282-288. doi:10.1016/ j.wneu.2017.05.165

16. Matsuzaki S, Serada S, Hiramatsu K, et al. Anti-glypican-1 antibody-drug conjugate exhibits potent preclinical antitumor activity against glypican-1 positive uterine cervical cancer. Int $J$ Cancer. 2018;142(5):1056-1066. doi:10.1002/ijc.31124

17. Suhovskih AV, Mostovich LA, Kunin IS, et al. Proteoglycan expression in normal human prostate tissue and prostate cancer. ISRN Oncol. 2013;2013:680136. doi:10.1155/2013/680136

18. Nagarajan A, Malvi P, Wajapeyee N. Heparan sulfate and heparan sulfate proteoglycans in cancer initiation and progression. Front Endocrinol (Lausanne). 2018;9:483. doi:10.3389/ fendo.2018.00483

19. Lewis JM, Vyas AD, Qiu Y, Messer KS, White R, Heller MJ. Integrated analysis of exosomal protein biomarkers on alternating current electrokinetic chips enables rapid detection of pancreatic cancer in patient blood. ACS Nano. 2018;12(4):3311-3320. doi:10.1021/acsnano.7b08199

20. Somarelli JA, Gardner H, Cannataro VL, et al. Molecular biology and evolution of cancer: from discovery to action. Mol Biol Evol. 2020;37 (2):320-326. doi:10.1093/molbev/msz242

21. Mundhenke C, Meyer K, Drew S, Friedl A. Heparan sulfate proteoglycans as regulators of fibroblast growth factor-2 receptor binding in breast carcinomas. Am J Pathol. 2002;160(1):185-194. doi:10.1016/ S0002-9440(10)64362-3

22. Xiang -Y-Y, Ladeda V, Filmus J. Glypican-3 expression is silenced in human breast cancer. Oncogene. 2001;20(50):7408-7412. doi:10.10 38/sj.onc. 1204925

23. Peters M, Farias E, Colombo L, Filmus J, Puricelli L, de Kier Joffé EB. Inhibition of invasion and metastasis by glypican-3 in a syngeneic breast cancer model. Breast Cancer Res Treat. 2003;80 (2):221-232. doi:10.1023/A:1024549729256

24. Stigliano I, Puricelli L, Filmus J, Sogayar MC, de Kier Joffé EB, Peters MG. Glypican-3 regulates migration, adhesion and actin cytoskeleton organization in mammary tumor cells through wnt signaling modulation. Breast Cancer Res Treat. 2009;114(2):251-262. doi:10. 1007/s10549-008-0009-2

25. Munir J, Van Ngu T, Ayudthaya PDN, Ryu S. Downregulation of glypican-4 facilitates breast cancer progression by inducing cell migration and proliferation. Biochem Biophys Res Commun. 2020;526(1):91-97. doi:10.1016/j.bbrc.2020.03.064

26. Yiu GK, Kaunisto A, Chin YR, Toker A. Nfat promotes carcinoma invasive migration through glypican-6. Biochem J. 2011;440 (1):157-166. doi:10.1042/BJ20110530

27. Li N, Spetz MR, Ho M. The role of glypicans in cancer progression and therapy. $J$ Histochem Cytochem. 2020;68(12):841-862. doi:10.1369/0022155420933709 
28. Lu H, Niu F, Liu F, Gao J, Sun Y, Zhao X. Elevated glypican-1 expression is associated with an unfavorable prognosis in pancreatic ductal adenocarcinoma. Cancer Med. 2017;6(6):1181-1191. doi:10. 1002/cam4.1064

29. Melo SA, Luecke LB, Kahlert C, et al. Glypican-1 identifies cancer exosomes and detects early pancreatic cancer. Nature. 2015;523 (7559):177-182. doi:10.1038/nature14581

30. Campbell DH, Lund ME, Nocon AL, et al. Detection of glypican-1 (gpc-1) expression in urine cell sediments in prostate cancer. PLoS One. 2018;13(4):e0196017. doi:10.1371/journal.pone.0196017

31. Quach Truong IOJ, Nocon AL, Soon JT, Wissmueller S, Campbell DH, Walsh BJ. Glypican-1 as a biomarker for prostate cancer: isolation and characterization. J Cancer. 2016;7(8):1002. doi:10.7150/jca. 14645

32. Frampton AE, Prado MM, López-Jiménez E, et al. Glypican-1 is enriched in circulating-exosomes in pancreatic cancer and correlates with tumor burden. Oncotarget. 2018;9(27):19006. doi:10.18632/ oncotarget. 24873
33. Melo S, Kahlert C, LeBleu V, Kalluri R. Multiple antibodies identify glypican-1 on serum exosomes from patients with pancreatic cancer. bioRxiv. 2017;145706. Available form: www.biorxiv.org/content/10. 1101/145706v3. Accessed July 28, 2021

34. Harada E, Serada S, Fujimoto M, et al. Glypican-1 targeted antibody-based therapy induces preclinical antitumor activity against esophageal squamous cell carcinoma. Oncotarget. 2017;8(15):24741. doi:10.18632/oncotarget. 15799

35. Nishigaki T, Takahashi T, Serada S, et al. Anti-glypican-1 antibody-drug conjugate is a potential therapy against pancreatic cancer. Br J Cancer. 2020;122(9):1333-1341. doi:10.1038/s4141 6-020-0781-2

36. Kato D, Yaguchi T, Iwata $T$, et al. Gpc1 specific car-t cells eradicate established solid tumor without adverse effects and synergize with anti-pd-1 ab. Elife. 2020;9:e49392. doi:10.7554/ eLife.49392

\section{Publish your work in this journal}

OncoTargets and Therapy is an international, peer-reviewed, open access journal focusing on the pathological basis of all cancers, potential targets for therapy and treatment protocols employed to improve the management of cancer patients. The journal also focuses on the impact of management programs and new therapeutic agents and protocols on patient perspectives such as quality of life, adherence and satisfaction. The manuscript management system is completely online and includes a very quick and fair peer-review system, which is all easy to use. Visit http://www.dovepress.com/ testimonials.php to read real quotes from published authors. 